\title{
COSTA RICA: IMPACTO DE LA IMPLEMENTACIÓN DEL IVA EN EL GASTO DE LOS HOGARES SEGÚN DECIL DE INGRESOS
}

\author{
COSTA RICA: IMPACT OF THE IMPLEMENTATION OF VAT ON HOUSEHOLD EXPENSES \\ ACCORDING TO DECIL OF INCOME
}

\section{COSTA RICA: IMPACTO DA IMPLEMENTAÇÃO DO IVA NAS DESPESAS DOMÉSTICAS DE ACORDO COM O DECIL DA RENDA}

\section{Fernando Rodríguez Garro ${ }^{1}$ \\ Roxana Morales Ramos ${ }^{2}$}

\begin{abstract}
Resumen
El 4 de diciembre de 2018 se publicó en La Gaceta de Costa Rica el Decreto Legislativo N.o 9635 titulado Fortalecimiento de las Finanzas Públicas, el cual, en su título I, realiza una reforma integral de la Ley N.으 6826 (Ley del Impuesto General sobre las Ventas) del 8 de noviembre de 1982. Esta ley transforma el impuesto general sobre las ventas (IGV) en un Impuesto al valor agregado (IVA), y establece diferentes tasas impositivas para diferentes subgrupos de bienes y servicios. El objetivo de este documento es presentar los resultados del análisis realizado sobre el impacto de la implementación del IVA sobre los diferentes deciles de ingreso en el país (cada decil se compone de un $10 \%$ de los hogares). Se determina que, si bien la mayor contribución monetaria (recaudación fiscal) estaría realizada por los hogares provenientes de los deciles más altos, son los hogares de los deciles inferiores los que serían
\end{abstract}

Doi: https://doi.org/10.15359/eys.24-56.3

Fecha de recepción: 11-06-2019. Fechas de reenvíos: 19-08-2019, 26-08-2019. Aceptado el 8-09-2019. Publicado el 09-09-2019.

Economía y Sociedad, así como los autores de este artículo, agradecen a José Francisco Pacheco Jiménez, exviceministro de Hacienda (Costa Rica) y a Suráyabi Alonso Ramírez Varas, investigador del Observatorio del Desarrollo de la Universidad de Costa Rica (UCR), por la revisión del documento y las observaciones realizadas.

${ }^{1}$ Economista. Máster en Política Económica por la Universidad Nacional (UNA), Costa Rica. Exviceministro de Hacienda, consultor internacional y académico de la Escuela de Economía de la UNA. Actualmente labora como investigador en el Observatorio Económico y Social (OES-UNA). Correo electrónico fernando.rodriguez.garro@gmail.com ORCID: https://orcid.org/0000-0003-2018-0187

${ }^{2}$ Economista. Máster en Economía de Desarrollo, con énfasis en Gestión Macroeconómica y Políticas Públicas por la Universidad Nacional (UNA), Costa Rica. Actualmente labora en la Escuela de Economía de la UNA, como académica y coordinadora del Observatorio Económico y Social (OES-UNA). Correo electrónico: rmorale@una.ac.cr ORCID: https://orcid.org/0000-0001-6609-6090 
más afectados en relación con su nivel de ingresos, ya que los primeros tres deciles -según la Encuesta nacional de ingresos y gastos de 2013gastan más de lo que obtienen por ingresos, lo que implica que el pago de una mayor cantidad de impuestos afectará, de manera importante, su capacidad de consumo, por lo que se requerirá del apoyo del Estado para contrarrestar este efecto.

Palabras claves: Reforma fiscal; impuesto al valor agregado; consumo; Ley de Fortalecimiento de las Finanzas Públicas.

\begin{abstract}
On December 4, 2018, the Legislative Decree No. 9635, entitled Strengthening of Public Finances was published in La Gaceta de Costa Rica; in its title No. 1, it carries out a comprehensive reform of Law No. 6826 (General Sales Tax Law) from November 8, 1982. This reform transforms the General Sales Tax (GST) into a Value Added Tax (VAT), establishing different tax rates for different subgroups of goods and services. The objective of this research is to present the results of the analysis carried out on the impact of the implementation of VAT on the different income deciles in the country (each decile is composed of $10 \%$ of households). It is determined that although the highest monetary contribution (tax collection) would be made by the households from the highest deciles, it is the households of the lower deciles that would be most affected in relation to their level of income, since, -according to the National Income and Expenditure Survey of 2013 - the first three deciles spend more than they earn. This means that the payment of more taxes will significantly affect their consumption capacity, which will require State support to counteract the effect.
\end{abstract}

Keywords: Tax reform; value added tax; consumption; Law on Strengthening Public Finance.

\title{
Resumo
}

Em 4 de dezembro de 2018, o Decreto Legislativo no 9635, intitulado Fortalecimento das Finanças Públicas, foi publicado em La Gaceta da Costa Rica, que, em seu título I, realiza uma ampla reforma da Lei no 6826 (Lei de Imposto Geral de Vendas) de 8 de novembro de 1982. Esta lei transforma o imposto geral sobre vendas (IGV) em um imposto sobre valor agregado (IVA) e estabelece diferentes taxas de imposto para diferentes subgrupos de bens e serviços. O objetivo deste documento é apresentar os resultados da análise realizada sobre o impacto da 
implementação do IVA nos diferentes decis de renda do país (cada decil é composto por $10 \%$ das famílias). Conclui-se que, embora a maior contribuição monetária (arrecadação de impostos) fosse feita pelos domicílios dos mais altos decis, são os domicílios dos menores decis que seriam os mais afetados em relação ao seu nível de renda, pois os primeiros três decis, de acordo com a Pesquisa Nacional de Renda e Despesas de 2013, gastam mais do que recebem como receita, o que implica que o pagamento de uma quantidade maior de impostos afetará significativamente sua capacidade de consumo, portanto exigirá o apoio do Estado para combater esse efeito.

Palavras-chaves: Reforma fiscal; imposto sobre valor agregado; consumo; Lei de Fortalecimento das Finanças Públicas.

\section{Introducción ${ }^{3}$}

El proyecto de ley denominado Ley de Fortalecimiento de las Finanzas Públicas, expediente 20.580 (aprobado en segundo debate por la Asamblea Legislativa de Costa Rica el lunes 3 de diciembre de 2018, con 34 votos a favor y 17 en contra y, publicado en la Gaceta el martes 4 de diciembre de 2018 -Ley N. ${ }^{\circ}$ 9635-) establece, entre otros aspectos, la transformación del impuesto general sobre las ventas (IGV) a un Impuesto sobre el valor agregado (IVA) ${ }^{4}$.

El objetivo de este trabajo es determinar el posible efecto de la implementación del IVA, sobre el consumo de los hogares. Para realizar las estimaciones se tomaron los datos de la Encuesta nacional de ingresos y gastos de los hogares (ENIG) realizada por el Instituto Nacional de Estadística y Censos (INEC) (2013), que cuenta un listado de 2684 bienes y servicios consumidos por los hogares costarricenses, en distintos montos, según el decil de ingreso.

Para realizar el análisis, se establecieron cinco subgrupos de acuerdo con el tratamiento tributario establecido en la Ley aprobada:

a) el que seguirá gravado con un $13 \%$ (al igual que cuando estuvo vigente el IGV),

b) el que será gravado por primera vez con un $13 \%$,

\footnotetext{
3 Una versión preliminar de algunos de los cálculos aquí mostrados se hizo pública pocos días después de la aprobación de la Ley N. ${ }^{\circ}$ 9635, con resultados diferentes. Esta diferencia se explica por dos razones: en la primera versión los cálculos se hicieron con base en la Ley del Impuesto General sobre las Ventas y no con el Reglamento de la Canasta Tributaria (que sí se usó en esta ocasión), además se revisaron los cálculos del estudio y se actualizaron los listados de los bienes gravados en los distintos niveles de tasa del impuesto.

${ }^{4}$ Mediante el Decreto Legislativo N.o 9635 (Fortalecimiento de las Finanzas Públicas), la Asamblea Legislativa de la República de Costa Rica decreta en su Título I (Ley del Impuesto al Valor Agregado) la reforma integral de la Ley N.을 $\underline{6826}$ (Ley del Impuesto General sobre las Ventas) del 8 de noviembre de 1982.
} 
c) el que será gravado con un $4 \%$,

d) el que será gravado con un $2 \% \mathrm{y}$,

e) el subgrupo de bienes de la llamada canasta básica, que será gravado con un $1 \%$.

En cada caso, con excepción del primer subgrupo (que actualmente se encuentra gravado), se multiplica el monto promedio consumido por cada decil por el porcentaje del impuesto respectivo, lo que permite obtener el nuevo monto de gasto (cuando entre en vigencia toda la reforma ${ }^{5}$ ). Aunque son pocos, hay algunos bienes que requirieron un ajuste adicional, que fueron aquellos que antes estaban gravados y ahora pasaron a estar exentos.

En el caso de los bienes de la canasta básica, para definir este subgrupo que no está explícitamente definido en la reforma, se tomó el listado de bienes de consumo básico que están exentos del impuesto al valor agregado, incluido en el Decreto Ejecutivo 41.615-MEIC-H, publicado en el Alcance N. ${ }^{\circ} 58$ de La Gaceta del 18 de marzo del 2019. Es importante indicar que el listado de bienes que será gravado con un $1 \%$ no está expresamente definido en la Ley N. ${ }^{\circ}$ 9635, sino que deberá ser determinado, vía decreto ejecutivo, y será actualizado cada vez que estén disponibles nuevos datos sobre el consumo de los hogares 6 . Este es un tema importante, pues las conclusiones que derivan de este análisis pueden variar en el futuro.

En la primera parte del documento se presentan algunas consideraciones sobre los impuestos al consumo y su efecto de regresividad; seguidamente, se exponen aspectos de la Encuesta nacional de ingresos y gastos (ENIG), base para realizar el análisis. Posteriormente, se exponen algunas características de los hogares costarricenses por decil de ingresos. En el apartado cuatro, se analiza el impacto sobre el gasto y el ingreso de los hogares, con la implementación del IVA, según cada subgrupo de tratamiento tributario. En el apartado cinco, se considera el gasto mensual adicional (gasto marginal) por hogar que deberá enfrentar cada decil de ingreso con la implementación de la Reforma Fiscal y, en el apartado seis, se exponen las principales conclusiones de la investigación.

\section{Los impuestos al consumo y su efecto de regresividad}

Los impuestos al consumo gravan el gasto que las personas o familias realizan en bienes y servicios, como una forma indirecta de gravar la capacidad contributiva de esas personas o

\footnotetext{
${ }^{5}$ Los primeros cambios de la reforma entraron en vigencia el 18 de abril de 2019, otros el 1 de julio de 2019 y los restantes (el cobro del $1 \%$ a los bienes de la canasta básica) entrarán en vigencia el 1 de julio de 2020.

6 "Para todos los efectos, la canasta básica será establecida mediante decreto ejecutivo emitido por el Ministerio de Hacienda y el Ministerio de Economía, Industria y Comercio (MEIC), y será revisada y actualizada cada vez que se publiquen los resultados de una nueva encuesta nacional de ingresos y gastos de los hogares. Esta canasta se definirá con base en el consumo efectivo de bienes y servicios de primera necesidad de los hogares que se encuentren en los dos primeros deciles de ingresos, de acuerdo con los estudios efectuados por el Instituto Nacional de Estadística y Censos (INEC)" (Ley N..$^{\circ}$ 9635, p, 12).
}

Fernando Rodríguez Garro / Roxana Morales Ramos

Revista Economía y Sociedad by Universidad Nacional is licensed under a CreativeCommons Reconocimiento-NoComercial- 
familias. Si bien este tipo de impuestos no está proporcionalmente ajustado al ingreso, como en el caso de los impuestos directos (el impuesto sobre la renta, por ejemplo), se parte del supuesto de que la capacidad de consumo de las personas está directamente relacionada con su poder adquisitivo. No obstante, el consumo de las personas difiere entre los diferentes niveles de ingreso, disminuyendo este en relación con el ingreso cuando el ingreso crece mucho, lo que provoca problemas para que los impuestos al consumo se ajusten a la capacidad contributiva de la gente y, por tal razón, se consideran regresivos.

Un impuesto regresivo se define como tal cuando su tarifa efectiva, o sea, el impuesto real pagado entre el ingreso de la persona o familia se reduce conforme el ingreso aumenta. Como la propensión a consumir ${ }^{7}$ de una persona o familia se reduce conforme su ingreso aumenta, la tasa efectiva de un impuesto al consumo disminuye al aumentar el ingreso, lo que convierte un impuesto al consumo en un impuesto regresivo. A pesar de su regresividad, y considerando deseable que una persona pague en proporción a su ingreso o que incluso que pague proporcionalmente más $^{8}$, los impuestos al consumo tienen la ventaja de que son importantes herramientas de recaudación y la resistencia de sus contribuyentes a pagarlo tiende a ser menor que en el caso de los impuestos directos: los contribuyentes de los impuestos al consumo no realizan declaraciones ante la administración tributaria y hacen su pago como parte del precio de un bien o servicio.

El impuesto al valor agregado es un impuesto al consumo, el cual recae sobre las fases de agregación de valor de un bien o servicio, de forma tal que el impuesto se vaya trasladando en esas fases de agregación de valor hasta llegar al contribuyente del impuesto, que es el público consumidor final del bien o servicio. El impuesto al valor agregado en su forma más común tiene la particularidad de que, a pesar de que grava los bienes y servicios finales, el sujeto pasivo del impuesto, o sea, el obligado tributario, es la empresa o negocio que vende el bien o servicio, de forma tal que las personas o familias pagan el impuesto incluido en el valor de lo que consumen (García, 2004). Pero, aunque el impuesto lo liquidan las empresas o negocios, son las personas o familias contribuyentes de este mismo, por lo que el IVA tiene los mismos problemas de regresividad que otros impuestos al consumo.

\section{Aspectos de la Encuesta nacional de ingresos y gastos de los hogares}

La Encuesta nacional de ingresos y gastos de los hogares, utilizada como referencia para este estudio, fue realizada por el Instituto Nacional de Estadística y Censos (INEC) entre octubre de

\footnotetext{
${ }^{7}$ La propensión a consumir es un concepto introducido en la teoría económica por el economista británico John Maynard Keynes (1883-1946), que se basa en la idea de que el consumo crece cuando el ingreso aumenta, pero en una proporción cada vez menor con respecto al crecimiento del ingreso. De esta forma la propensión a consumir de una persona de ingresos bajos es mayor que la propensión marginal a consumir de una persona de ingresos altos. ${ }^{8}$ Concepto conocido como equidad vertical, cuando las personas pagan proporcionalmente más cuando sus ingresos son mayores.
}

Fernando Rodríguez Garro / Roxana Morales Ramos 
2012 y octubre de 2013, con una muestra de 7020 viviendas de las cuales se dispone de información final para 5705 hogares (INEC, 2013). Esta encuesta provee información sobre la composición del presupuesto de los hogares en Costa Rica (ingresos y su distribución en la compra de bienes y servicios).

EI INEC, a la fecha, ha realizado seis encuestas sobre ingresos y gastos de los hogares, la más reciente disponible es la de 2013. Actualmente se está elaborando una nueva encuesta, la cual inició en 2018 y se espera sea publicada a finales de 2019, con lo que se tendrá nueva información para realizar el análisis de impacto del IVA sobre los hogares y, además, permitirá la definición de una nueva canasta básica tributaria.

\section{Características de los hogares según decil de ingreso}

Por decil de ingreso se entiende la agrupación de los hogares según su ingreso per cápita, de menor a mayor ingreso, en diez grupos de igual tamaño. Cada decil se compone de un $10 \%$ de los hogares.

En la Tabla 1 se presenta información sobre la cantidad de hogares que componen cada decil, la cantidad de personas, el ingreso corriente bruto (incluye el ingreso por trabajo, el ingreso por rentas, las transferencias corrientes recibidas y el valor imputado de la vivienda) y la distribución porcentual del ingreso. De esta información resalta que los hogares de los deciles más bajos son más numerosos, por lo que la cantidad de personas ubicadas en estos deciles es mayor que la de los deciles más altos.

Con respecto al ingreso promedio de los hogares, el del decil 10 es 16,1 veces mayor que el del decil 1, evidenciándose una importante brecha (por persona la brecha es de 29,5 veces).

Por su parte, si se suman todos los ingresos promedio de los hogares del país (del decil 1 al decil 10), los deciles 9 y 10 representan el $51 \%$ de ese total, mientras que los del decil 1 y 2 apenas representan el 5,5\% (41503 colones por persona).

Esta importante brecha en los ingresos también se reproduce en el consumo. En la Tabla 2 se observa que los hogares de los deciles más altos son los que más consumen, pero a su vez son los que menos proporción de su ingreso gastan: mientras que los deciles 1,2 y 3 consumen mensualmente un monto mayor que sus ingresos (ver relación gasto/ingreso en la Tabla 2), los últimos deciles más bien tienen la posibilidad de ahorrar/invertir (su consumo no excede el ingreso).

Esta información es importante, ya que los hogares de los deciles más altos son los que pueden hacer -más fácilmente- frente al pago de nuevos impuestos, mientras que los hogares de los deciles más bajos tienen prácticamente nula capacidad de aumentar su gasto, es decir, para poder 
pagar nuevos impuestos deberán reducir la cantidad/calidad de los bienes y servicios consumidos o requerirán de mayores transferencias del Estado para poder mantener su nivel de consumo real.

Tabla 1

Hogares, personas, promedio de ingreso corriente bruto mensual por hogar y per cápita según decil de ingreso. Octubre 2012 - octubre 2013

\begin{tabular}{cccccccc}
\hline & & \multirow{2}{*}{$\begin{array}{c}\text { Promedio } \\
\text { Decil }\end{array}$} & \multicolumn{2}{c}{ Personas } & \multicolumn{2}{c}{$\begin{array}{c}\text { Ingreso corriente } \\
\text { bruto }\end{array}$} & $\begin{array}{c}\text { Distribución } \\
\text { porcentual del } \\
\text { ingreso por } \\
\text { personas }\end{array}$ \\
\cline { 5 - 7 } & & por hogar & Total & $\begin{array}{c}\text { Distribución } \\
\text { porcentual }\end{array}$ & Por hogar & Per cápita & $\begin{array}{c}\text { ingar } \\
\text { hogar }\end{array}$ \\
\hline Total & $\mathbf{1 . 3 9 6 . 7 4 7}$ & $\mathbf{3 , 4}$ & $\mathbf{4 . 6 9 7 . 0 0 2}$ & $\mathbf{1 0 0 , 0 \%}$ & $\mathbf{8 5 0 . 1 9 5}$ & $\mathbf{2 9 9 . 9 0 9}$ & $\mathbf{1 0 0 \%}$ \\
I & 139.805 & $\mathbf{4 , 4}$ & 608.997 & $13,0 \%$ & 179.502 & $\mathbf{4 1 . 5 0 3}$ & $\mathbf{2 , 1 \%}$ \\
II & 139.239 & $\mathbf{4 , 0}$ & 558.597 & $11,9 \%$ & 288.213 & 71.783 & $3,4 \%$ \\
III & 140.240 & 3,5 & 500.850 & $10,7 \%$ & 341.614 & 95.224 & $4,0 \%$ \\
IV & 139.402 & 3,6 & 509.254 & $10,8 \%$ & 446.862 & 121.676 & $5,3 \%$ \\
V & 139.952 & 3,5 & 484.870 & $10,3 \%$ & 527.404 & 151.233 & $6,2 \%$ \\
VI & 139.485 & 3,3 & 464.069 & $9,9 \%$ & 633.560 & 190.023 & $7,5 \%$ \\
VII & 139.597 & 3,1 & 415.941 & $8,9 \%$ & 730.190 & 243.839 & $8,6 \%$ \\
VIII & 139.812 & 3,0 & 421.675 & $9,0 \%$ & 1.024 .336 & 338.927 & $12,0 \%$ \\
IX & 139.483 & 2,8 & 388.231 & $8,3 \%$ & 1.441 .591 & 519.517 & $17,0 \%$ \\
X & 139.732 & 2,5 & 344.518 & $7,3 \%$ & 2.888 .911 & $\mathbf{1 . 2 2 5 . 3 7 2}$ & $\mathbf{3 4 , 0 \%}$ \\
\hline
\end{tabular}

Nota: Elaboración propia con datos de la ENIG 2013 del INEC.

Tabla 2

Hogares, personas, promedio de gasto corriente bruto mensual por hogar y per cápita según decil de ingreso. Octubre 2012 - octubre 2013

\begin{tabular}{|c|c|c|c|c|c|c|}
\hline \multirow[b]{2}{*}{ Decil } & \multirow[b]{2}{*}{ Hogares } & \multirow{2}{*}{$\begin{array}{c}\text { Promedio } \\
\text { personas por } \\
\text { hogar }\end{array}$} & \multicolumn{2}{|c|}{ Gasto corriente } & \multirow{2}{*}{$\begin{array}{c}\text { Distribución } \\
\text { porcentual del } \\
\text { gasto por hogar }\end{array}$} & \multirow{2}{*}{$\begin{array}{c}\text { Relación } \\
\text { Gasto/Ingreso } \\
\text { por hogar }\end{array}$} \\
\hline & & & Por hogar & Per cápita & & \\
\hline Total & 1.396 .747 & 3,4 & 701.571 & 247.959 & $100 \%$ & 0,83 \\
\hline 1 & 139.805 & 4,4 & 249.094 & 60.806 & $3,6 \%$ & 1,39 \\
\hline II & 139.239 & 4,0 & 325.972 & 83.437 & $4,6 \%$ & 1,13 \\
\hline III & 140.240 & 3,5 & 353.111 & 101.479 & $5,0 \%$ & 1,03 \\
\hline IV & 139.402 & 3,6 & 438.235 & 124.870 & $6,2 \%$ & 0,98 \\
\hline V & 139.952 & 3,5 & 495.716 & 144.518 & $7,1 \%$ & 0,94 \\
\hline VI & 139.485 & 3,3 & 562.024 & 177.296 & $8,0 \%$ & 0,89 \\
\hline VII & 139.597 & 3,1 & 663.601 & 224.374 & $9,5 \%$ & 0,91 \\
\hline VIII & 139.812 & 3,0 & 838.702 & 285.629 & $12,0 \%$ & 0,82 \\
\hline IX & 139.483 & 2,8 & 1.143 .764 & 424.922 & $16,3 \%$ & 0,79 \\
\hline$x$ & 139.732 & 2,5 & 1.945 .797 & 852.324 & $27,7 \%$ & 0,67 \\
\hline
\end{tabular}

Fuente: Elaboración propia con datos de la ENIG 2013 del INEC. 


\section{Impacto de la aplicación del IVA en el gasto corriente de los hogares}

A continuación, se presenta el análisis para cuatro subgrupos, de acuerdo con el porcentaje de impuesto establecido en la Ley de Fortalecimiento de la Finanzas Públicas para cada uno.

\section{a) Servicios que empezarían a gravarse con el $13 \%$}

De los 2684 bienes y servicios analizados, aproximadamente un 3,5\% se estaría gravando por primera vez con el IVA correspondiente al $13 \%$ (servicios que no estaban gravados con el IGV). Esto, debido a que un grupo importante de los servicios que más consumen los hogares (servicios de telefonía, internet y electricidad, servicio de restaurante, talleres de reparación y pintura de vehículos, servicios de lavado y encerado de vehículos, entre otros), ya pagaban el $13 \%$ de IGV (Ley N. ${ }^{\circ}$ 6826, Ley del Impuesto General sobre las Ventas).

Los servicios que empezarían a pagar impuestos representan un porcentaje bastante bajo en el gasto total mensual promedio de los hogares. En la Tabla 3 se muestra el peso de esos servicios en el total del gasto de los hogares, por decil de ingreso.

Tabla 3

Participación de los servicios que empezarían a gravarse con un IVA del $13 \%$ en el gasto corriente de los hogares, según decil de ingreso

\begin{tabular}{cccccccccc}
\hline Decil 1 & Decil 2 & Decil 3 & Decil 4 & Decil 5 & Decil 6 & Decil 7 & Decil 8 & Decil 9 & Decil 10 \\
\hline 1,31\% & $0,78 \%$ & $1,34 \%$ & $1,04 \%$ & $2,04 \%$ & $1,08 \%$ & $2,34 \%$ & $2,29 \%$ & $2,75 \%$ & $2,94 \%$
\end{tabular}

Fuente: elaboración propia, con base en datos de la ENIG 2013.

Como se observa en la Tabla 3 , el porcentaje del gasto de los hogares en estos servicios que empezarían a gravarse es muy pequeño, pero creciente según el aumento del ingreso promedio de los hogares (a mayor decil, más peso). Ello hace pensar que el impuesto sobre este grupo de servicios es progresivo en relación con el consumo.

\section{b) Servicios que empezarían a gravarse con el $4 \%$}

Los servicios que se estarían gravando con un $4 \%$ de IVA, que incluyen principalmente servicios privados de salud, también tienen una distribución creciente según aumenta el ingreso de los hogares, lo que hace presuponer que el impuesto sobre este grupo de servicios también es progresivo con respecto al consumo (Ver Tabla 4). Sin embargo, llama la atención el peso que tiene sobre el decil 4, lo que se podría considerar población vulnerable, pues sus ingresos y su nivel de gasto podrían acercarlos eventualmente a la condición de pobreza. 
Tabla 4

Participación de los servicios que empezarían a gravarse con el IVA a un $4 \%$ en el gasto corriente de los hogares según decil de ingreso

\begin{tabular}{cccccccccc}
\hline Decil 1 & Decil 2 & Decil 3 & Decil 4 & Decil 5 & Decil 6 & Decil 7 & Decil 8 & Decil 9 & Decil 10 \\
\hline $0,51 \%$ & $0,55 \%$ & $0,69 \%$ & $1,27 \%$ & $0,82 \%$ & $0,82 \%$ & $1,42 \%$ & $1,20 \%$ & $1,46 \%$ & $1,29 \%$ \\
\hline
\end{tabular}

Fuente: elaboración propia, con base en datos de la ENIG 2013.

Es importante indicar que la Ley aprobada dispone que el impuesto pagado por los servicios de salud pueda ser devuelto a los consumidores de estos servicios, siempre y cuando utilicen tarjetas de débito o crédito como medio de pago, aunque para efectos de este análisis se va a prescindir de esa posibilidad (no se considera la devolución de impuestos por este rubro, ya que no todo el público consumidor de estos servicios utilizará las tarjetas como medio de pago).

Al respecto, la Ley $\mathrm{N}^{\circ} 9635$ establece:

Con independencia de lo dispuesto en los párrafos precedentes, tratándose de la compra de servicios de salud privados, establecidos en el artículo 11, inciso 1, subinciso b), que hayan sido cancelados por medio de tarjeta de crédito, débito o cualquier otro medio electrónico que autorice la Administración Tributaria, la totalidad del impuesto pagado por los consumidores finales de estos servicios constituirá un crédito a favor del adquirente del servicio y procederá su devolución como plazo máximo dentro de los quince días siguientes del mes posterior a su adquisición, de conformidad con el procedimiento que se establezca reglamentariamente. (Ley 9635 , p.22)

Finalmente, en el Reglamento del IVA, publicado en La Gaceta del 11 de junio de 2019, se estableció en el Artículo 39, la devolución inmediata del IVA del $4 \%$ y, por tanto, su cobro entró a regir el 01 de julio de 2019. Este mecanismo estableció que quien presta los servicios de salud humana privados, factura el IVA, pero no lo cobra a su cliente si el pago es realizado mediante tarjeta de débito o crédito.

\section{c) Servicios que empezarían a gravarse con el $2 \%$}

En el caso de los bienes y servicios sujetos a un impuesto del $2 \%{ }^{9}$, el gasto promedio de los hogares en estos productos es igualmente bajo, pero en cuanto a la participación de este rubro

\footnotetext{
${ }^{9}$ Medicamentos; materias primas, los insumos, la maquinaria, el equipo y los reactivos necesarios para la producción de medicamentos; primas de seguros personales; compra y venta de bienes y servicios que realicen las Universidades públicas, sus fundaciones, las instituciones estatales parauniversitarias, el Consejo Nacional de Rectores (CONARE) y el Sistema Nacional de Acreditación de la Educación Superior (SINAES); los servicios de educación privada no exentos en el artículo 11 de la Ley N. ${ }^{\circ} 9635$.
}

Fernando Rodríguez Garro / Roxana Morales Ramos

Revista Economía y Sociedad by Universidad Nacional is licensed under a CreativeCommons Reconocimiento-NoComercial- 
en el gasto de los hogares, según decil de ingreso, los porcentajes son más planos y no tienen un comportamiento creciente.

Sobre este impuesto es importante mencionar que el efecto sobre los hogares de más bajos ingresos es significativo, ya que como se mencionó anteriormente, estos hogares consumen actualmente más de lo que tienen de ingresos y cualquier aumento en el costo de los bienes y servicios consumidos implicará una reducción del consumo real (Ver Tabla 5 ).

Tabla 5

Participación de los servicios que pasarán a gravarse con el IVA a un $2 \%$ en el gasto corriente de los hogares según decil de ingreso

\begin{tabular}{cccccccccc}
\hline Decil 1 & Decil 2 & Decil 3 & Decil 4 & Decil 5 & Decil 6 & Decil 7 & Decil 8 & Decil 9 & Decil 10 \\
\hline $0,87 \%$ & $0,95 \%$ & $0,96 \%$ & $1,00 \%$ & $1,05 \%$ & $1,01 \%$ & $1,12 \%$ & $1,11 \%$ & $1,44 \%$ & $1,17 \%$ \\
\hline
\end{tabular}

Fuente: elaboración propia, con base en datos de la ENIG, 2013.

\section{d) Canasta básica gravada con el $1 \%$ de IVA}

Finalmente, están los bienes de la canasta básica que quedan gravados con un IVA del $1 \%$ (en la ley del IGV estaban exentos los bienes incluidos en la canasta básica tributaria). En este caso estamos ante bienes de primera necesidad, principalmente, cuya participación en el gasto de los deciles de menores ingresos es mucho mayor y se va reduciendo conforme aumenta el ingreso familiar, debido a que se incorporan otras opciones de gasto con un peso mayor.

Tabla 6

Participación de los bienes que pasarán a gravarse con el IVA a un $1 \%$ en el gasto corriente de los hogares, según decil de ingreso

\begin{tabular}{cccccccccc}
\hline Decil 1 & Decil 2 & Decil 3 & Decil 4 & Decil 5 & Decil 6 & Decil 7 & Decil 8 & Decil 9 & Decil 10 \\
\hline $23,01 \%$ & $20,70 \%$ & $18,72 \%$ & $14,90 \%$ & $14,62 \%$ & $11,89 \%$ & $10,04 \%$ & $7,83 \%$ & $4,66 \%$ & $2,71 \%$ \\
\hline
\end{tabular}

Fuente: elaboración propia, con base en datos de la ENIG, 2013.

Es evidente que, en este caso, la aplicación de una tarifa de impuesto tendrá un efecto regresivo, desde la perspectiva del consumo, pues pesará más en los gastos de los deciles de menores ingresos que en las familias de mayor ingreso ( $\underline{\text { Tabla } 6 \text { ). }}$.

\section{Impacto de la aplicación del IVA en los ingresos promedio de los hogares}

Las apreciaciones que se hacen en las Tablas $\underline{3}, \underline{4}, \underline{5}$ y $\underline{6}$, con respecto al peso de los distintos bienes y servicios que empezarían a pagar impuestos con la reforma del IVA, varían sustancialmente cuando se compara ese gasto con los ingresos percibidos por esos deciles (ver Tabla 7) 
Tabla 7

Gasto en bienes y servicios que pasarán a gravarse con el IVA como porcentaje del ingreso corriente de las familias, por decil de ingreso

\begin{tabular}{ccccccccccc}
\hline IVA & Decil 1 & Decil 2 & Decil 3 & Decil 4 & Decil 5 & Decil 6 & Decil 7 & Decil 8 & Decil 9 & Decil 10 \\
\hline IVA 13\% & $\mathbf{2 , 2 8 \%}$ & $1,17 \%$ & $1,83 \%$ & $1,37 \%$ & $2,66 \%$ & $1,32 \%$ & $3,07 \%$ & $2,88 \%$ & $3,57 \%$ & $3,67 \%$ \\
IVA 4\% & $0,88 \%$ & $0,81 \%$ & $0,95 \%$ & $1,69 \%$ & $1,07 \%$ & $1,01 \%$ & $1,86 \%$ & $1,50 \%$ & $1,89 \%$ & $1,60 \%$ \\
IVA 2\% & $1.51 \%$ & $1.40 \%$ & $1.31 \%$ & $1.33 \%$ & $1.38 \%$ & $1.24 \%$ & $1.48 \%$ & $1.39 \%$ & $1.87 \%$ & $1.45 \%$ \\
IVA 1\% & $40,1 \%$ & $30,7 \%$ & $25,5 \%$ & $19,8 \%$ & $19,1 \%$ & $14,6 \%$ & $13,2 \%$ & $9,83 \%$ & $6,05 \%$ & $3,37 \%$ \\
\hline
\end{tabular}

Fuente: elaboración propia, con base en datos de la ENIG, 2013.

Debido a que los primeros tres deciles tienen un nivel de gasto superior al de sus ingresos, los números varían al comparar el gasto en los bienes y servicios que pagarán IVA con respecto al gasto de los hogares y en relación con el ingreso de estos.

- La regresividad del impuesto a la canasta básica (1\%) sigue siendo muy marcada, mucho más aún si se compara con los ingresos de las familias en los distintos deciles.

- El impuesto a servicios médicos privados (4 \%) aún mantiene un leve efecto de progresividad.

- En el caso del IVA del $2 \%$, ya no se observa la poca progresividad que había al comparar el gasto en este nuevo impuesto con respecto al gasto de los hogares.

- En cuanto a los servicios que se gravarían con un $13 \%$, llama la atención el peso que tienen estos en el ingreso promedio del primer decil $(2,28 \%)$, ya que es mayor que el peso en el ingreso del decil 2, 3, 4 y 6 .

\section{Gasto adicional que deberán enfrentar las familias con el IVA}

Es importante conocer cuál será el gasto adicional, producto de la reforma en el IVA, que deberán enfrentar (en promedio) las familias. Para ello se estimaron los efectos "brutos", es decir, no se consideró que en ciertos bienes y servicios el efecto pudiese ser menor por la aplicación de los créditos fiscales en los procesos productivos intermedios e iniciales, característicos de la aplicación de un impuesto al valor agregado.

Para el cálculo tampoco se consideró el efecto neto de la posibilidad de que el impuesto pagado en los servicios privados de salud sea devuelto a los consumidores de estos que hayan pagado con tarjeta de crédito o débito, ni se incluye el IVA del $13 \%$ sobre el alquiler de viviendas, ya que el límite exento quedó bastante alto y muy pocos hogares tendrían que pagar este impuesto (alrededor de 669 mil colones mensuales) ${ }^{10}$ :

\footnotetext{
${ }^{10}$ El Ministerio de Hacienda estimó que alrededor del $80 \%$ de los hogares del país no deberán pagar IVA por alquiler de vivienda ya que pagan menos de 669 mil colones mensuales por este servicio.
} 
Los arrendamientos de inmuebles destinados exclusivamente a viviendas, así como los garajes y anexos accesorios a las viviendas y el menaje de casa, arrendado conjuntamente con aquellos, siempre y cuando el monto de la renta mensual sea igual o inferior al uno coma cinco $(1,5)$ del salario base. Cuando el monto de la renta mensual exceda del uno coma cinco $(1,5)$ del salario base, el impuesto se aplicará al total de la renta. También estarán exentos los pagos que realicen las organizaciones religiosas, cualquiera que sea su credo, por los alquileres en los locales o establecimientos en los que desarrollen su culto. (Ley N. ${ }^{\circ}$ 9635, Artículo 8, Exenciones)

Se han planteado, entonces, dos escenarios: uno que considera el incremento en el gasto familiar producto de la aplicación completa de la reforma del IVA (cuando entren en vigor todos los impuestos) y otro sin contemplar el IVA de $1 \%$ a la canasta básica tributaria, los cuales arrojan los siguientes resultados (Tabla 8):

Tabla 8

Gasto adicional mensual por hogar por efecto de la aplicación del IVA, por decil de ingreso

\begin{tabular}{lllllllllll}
\hline Escenario & Decil 1 & Decil 2 & Decil 3 & Decil 4 & Decil 5 & Decil 6 & Decil 7 & Decil 8 & Decil 9 & Decil 10 \\
\hline $\begin{array}{l}\text { Impacto completo } \\
\text { Impacto del IVA }\end{array}$ & $0.70 \%$ & $0.58 \%$ & $0.69 \%$ & $0.55 \%$ & $0.72 \%$ & $0.56 \%$ & $0.68 \%$ & $0.66 \%$ & $0.64 \%$ & $0.59 \%$ \\
\hline $\begin{array}{l}\text { Imp 1\% de la } \\
\begin{array}{l}\text { canasta básica } \\
\text { tributaria }\end{array}\end{array}$ & $0.47 \%$ & $0.35 \%$ & $0.49 \%$ & $0.38 \%$ & $0.57 \%$ & $0.44 \%$ & $0.58 \%$ & $0.58 \%$ & $0.59 \%$ & $0.57 \%$ \\
\hline
\end{tabular}

Fuente: elaboración propia, con base en datos de la ENIG, 2013.

El impacto de la aplicación del IVA en el gasto promedio de los hogares no implica la erogación de un monto adicional importante, pues en ninguno de los diez deciles de ingreso el gasto adicional superaría el $1 \%$ con respecto al escenario previo (sin reforma), situación que se explica por el hecho de que la reforma aprobada el año anterior viene a ampliar la base, en muchos casos con tarifas reducidas e incorporando pocos nuevos servicios a la base con una tarifa plena del 13 $\%$. Los resultados también pueden reflejar un sesgo de la propia Encuesta de ingresos y gastos, en el sentido de que esta refleja el consumo (gasto) que había en el país entre el 2012 y el 2013, momento desde el cual el consumo de servicios podría haber ganado importancia relativa en el consumo general de los hogares, por lo que los resultados podrían variar bastante, si este ejercicio se hace con la información de la ENIG que se deberá publicar en 2019.

Si bien la decisión de incorporar o no algún tipo de gravamen sobre la canasta básica tributaria implica una diferencia en el esfuerzo adicional que deberán hacer los hogares, este no será importante tampoco, como se puede notar en la Tabla 7. Esto se debe a que, como ya se mencionó, hoy muchos de los bienes que consumen los hogares están gravados (por ejemplo, ropa, comidas fuera del hogar, telefonía, internet, etc.), otros seguirán exonerados (como el 
transporte público) y en general el $1 \%$ de impuesto es una tasa bastante pequeña cuyo peso en el consumo final no es significativo.

En cuanto a ingresos y gastos de los hogares, la aplicación del IVA no va a generar mayor efecto, aunque evidentemente implica una mayor brecha de los ingresos y los gastos para los deciles 1 , 2 y 3 , cuya situación implicará, de alguna manera, algún esfuerzo adicional de la política pública (ver Tabla 9), sin que este sea inmanejable.

Tabla 9

Efecto de la aplicación del IVA por decil de ingreso de los hogares. En colones corrientes.

\begin{tabular}{lcccccrr}
\hline $\begin{array}{c}\text { Decil } \\
\text { de } \\
\text { ingreso }\end{array}$ & $\begin{array}{c}\text { Ingreso } \\
\text { corriente } \\
\text { bruto } \\
\text { mensual por } \\
\text { hogar }\end{array}$ & $\begin{array}{c}\text { Gasto } \\
\text { corriente } \\
\text { mensual } \\
\text { por hogar }\end{array}$ & $\begin{array}{c}\text { Diferencia } \\
\text { ingreso- } \\
\text { gasto }\end{array}$ & $\begin{array}{c}\text { \% de Gasto } \\
\text { adicional } \\
\text { mensual con } \\
\text { aplicación } \\
\text { total del IVA }\end{array}$ & $\begin{array}{c}\text { Gasto } \\
\text { adicional } \\
\text { mensual con } \\
\text { aplicación } \\
\text { total del IVA }\end{array}$ & $\begin{array}{c}\text { Gasto total } \\
\text { mensual con } \\
\text { implemtación } \\
\text { de IVA }\end{array}$ & $\begin{array}{c}\text { Diferencia } \\
\text { ingreso- } \\
\text { gasto con } \\
\text { IVA }\end{array}$ \\
\hline I & 179.502 & 249.094 & -69.592 & $0.70 \%$ & 1.747 & 250.841 & -71.339 \\
II & 288.213 & 325.972 & -37.759 & $0.58 \%$ & 1.883 & 327.855 & -39.642 \\
III & 341.614 & 353.111 & -11.497 & $0.69 \%$ & 2.438 & 355.549 & -13.935 \\
IV & 446.862 & 438.235 & 8.627 & $0.55 \%$ & 2.388 & 440.623 & 6.238 \\
V & 527.404 & 495.716 & 31.688 & $0.72 \%$ & 3.587 & 499.303 & 28.100 \\
VI & 633.560 & 562.024 & 71.536 & $0.56 \%$ & 3.146 & 565.170 & 68.389 \\
VII & 730.190 & 663.601 & 66.589 & $0.68 \%$ & 4.497 & 668.098 & 62.091 \\
VIII & 1.024 .336 & 838.702 & 185.634 & $0.66 \%$ & 5.573 & 844.275 & 180.060 \\
IX & 1.441 .591 & 1.143 .764 & 297.827 & $0.64 \%$ & 7.313 & 1.151 .077 & 290.513 \\
X & 2.888 .911 & 1.945 .797 & 943.114 & $0.59 \%$ & 11.545 & 1.957 .342 & 931.568 \\
\hline
\end{tabular}

Fuente: elaboración propia, con base en datos de la ENIG, 2013.

Un aspecto importante es que, a pesar de los esfuerzos por incluir una serie de exoneraciones y tratamientos diferenciados en el impuesto, que vendrán a complicar la administración del tributo y a abrir portillos para su evasión, el efecto marginal del IVA no será progresivo en función de los ingresos de las familias. Si se compara el esfuerzo adicional de las familias para atender las nuevas obligaciones tributarias que este impuesto implica, con respecto a los ingresos familiares promedio por decil (ver Tabla 10), se nota fácilmente que el esfuerzo que las familias de menores ingresos realizarán será mayor que el de las familias de mayores ingresos, sin que este efecto de ser relativamente pequeño (menor a un $1 \%$ ). 
Tabla 10

Gasto adicional mensual por hogar por efecto de la aplicación total del IVA y gasto corriente adicional con respecto a los ingresos corrientes promedios del hogar, por decil de ingreso

\begin{tabular}{|c|c|c|c|c|c|c|c|c|c|c|}
\hline Escenario & Decil 1 & Decil 2 & Decil 3 & Decil 4 & Decil 5 & Decil 6 & Decil 7 & Decil 8 & Decil 9 & Decil 10 \\
\hline $\begin{array}{l}\text { Impacto } \\
\text { completo }\end{array}$ & $0.70 \%$ & $0.58 \%$ & $0.69 \%$ & $0.55 \%$ & $0.72 \%$ & $0.56 \%$ & $0.68 \%$ & $0.66 \%$ & $0.64 \%$ & $0.59 \%$ \\
\hline $\begin{array}{l}\text { Gastos en } \\
\text { relación } \\
\text { con los } \\
\text { ingresos } \\
\text { familiares }\end{array}$ & $0.97 \%$ & $0.65 \%$ & $0.71 \%$ & $0.53 \%$ & $0.68 \%$ & $0.50 \%$ & $0.62 \%$ & $0.54 \%$ & $0.51 \%$ & $0.40 \%$ \\
\hline
\end{tabular}

Fuente: elaboración propia, con base en datos de la ENIG, 2013.

Las decisiones legislativas, tomadas en el trámite de aprobación del impuesto al valor agregado (IVA), no provocaron ninguna mejora en el impuesto, es decir, el IVA no es menos regresivo con esta propuesta, por lo que, si se quisiera inducir algún efecto diferente entre las familias por su nivel de ingreso, habrá que pensar en medidas diferentes para restarle efecto negativo al IVA en el futuro. Tomando en cuenta, además, que la actual reforma es insuficiente para lograr sostenibilidad fiscal en el largo plazo ${ }^{11}$, y que es posible que deba pensarse en un aumento en la tarifa vigente del IVA, es necesario, desde ya, pensar en una forma de compensar el impacto regresivo de este impuesto. Para eso debería valorarse el retomar la propuesta de devolución del IVA a las familias de los primeros cuatro deciles, que se había incorporado en el Proyecto de Ley N. ${ }^{\circ} 19.678$, Ley de Impuesto al Valor Agregado, presentado a la corriente legislativa en agosto de 2015.

\section{Conclusiones}

En términos generales el impacto de la implementación del IVA sobre el gasto de los hogares es reducido, la discusión que se dio durante el trámite de aprobación pudo haber sido excesiva por la ausencia de información sobre el impacto que esto iba a generar y, además, porque existe la percepción, en la población costarricense, de que en este país se pagan "muchos impuestos" o altos niveles de estos.

A pesar de lo anterior, es claro que el impuesto (el IGV que se transforma en IVA) con respecto al ingreso es regresivo, y su regresividad no se corrige con esta reforma, sino que más bien se refuerza ligeramente. La regresividad de un tributo con estas características es difícilmente corregible por medio de la manipulación de la base imponible, aunque valorando el hecho de que el efecto del impuesto en la canasta básica es más importante en los deciles más bajos y

\footnotetext{
${ }^{11}$ Observando el efecto que el IVA tendrá dentro del gasto familiar (según este estudio), pareciera también que su efecto recaudatorio será bastante limitado, incluso más de lo que hasta ahora se ha previsto.
} 
disminuye para los deciles más altos, se podría concluir que exonerar la canasta básica habría contribuido con restarle regresividad al impuesto, aunque ese efecto sería ínfimo, en virtud del poco impacto que la reforma tendrá en las finanzas familiares.

La inclusión del IVA en la canasta básica podría ayudar a mejorar la trazabilidad del impuesto que se aplica en la cadena de valor de los bienes de consumo básico, aunque quedará por verse, si ese efecto positivo no es compensado negativamente por las dificultades de gestión del tributo, que introduce el tratamiento con una tarifa diferenciada y reglas particulares para la acreditación de los impuestos pagados en las fases previas de generación de valor. Esta dificultad, igualmente, se podría presentar con los otros bienes y servicios que se están gravando con tarifas reducidas.

Considerando el poco peso que la introducción del IVA tendrá en los hogares del país, con respecto al existente impuesto general sobre las ventas, es factible prever que la recaudación adicional que genere esta reforma no será particularmente alta. Esto sucede por varias razones: la reforma no cambia la tasa que se estará cobrando del impuesto (el mismo 13 \%), ya muchos servicios de alto consumo de los hogares que están pagando el IGV (como telefonía e internet) y algunos servicios quedaron exentos (como el transporte, los alquileres por debajo de 1,5 salarios base por mes, el consumo de electricidad por debajo de los $280 \mathrm{kw} / \mathrm{h}$ mensuales y el consumo de agua por debajo de los 30 metros cúbicos al mes).

Un aspecto importante de destacar es que los cálculos que se presentan en este documento suponen que el efecto completo del impuesto se trasladará al consumidor, para el caso de aquellos bienes y servicios que pasarán a gravarse con la tarifa completa del IVA o con una tarifa reducida. Eso no necesariamente sucederá así: la aplicación de los créditos del impuesto y decisiones empresariales podrían implicar un menor "efecto traslado" del impuesto a los precios finales, por lo que el resultado en el gasto sería un máximo teórico y podría ser menor a lo indicado aquí. También, debido a la situación del consumo durante los primeros meses del 2019, actividad que ha sufrido por una fuerte caída en su ritmo de crecimiento, es posible que los productores y vendedores de los bienes y servicios que pasarían a gravarse no trasladen todo o una parte del impuesto al consumidor, para evitar una reducción mayor del consumo.

Finalmente, este trabajo se basa en los datos más recientes de la encuesta de ingresos y gastos de los hogares, que corresponde al consumo que los hogares costarricenses tenían entre 2012 y 2013. La aplicación de la misma metodología de trabajo a una versión posterior de la encuesta, muy probablemente arrojará datos distintos y una distribución diferente del impacto de la aplicación del IVA. 


\section{Referencias}

García, E. (2003). La economía de los impuestos. Madrid, España: Minerva Ediciones.

Instituto Nacional de Estadística y Censos (INEC). (2013). Encuesta nacional de ingresos y gastos de los hogares 2013. Recuperado de http://www.inec.go.cr/sites/default/files/documetos-bibliotecavirtual/meenigh2013.pdf

Ley N. ${ }^{\circ} 9635$. Fortalecimiento de las finanzas públicas. La Gaceta, 4 de diciembre de 2018. Alcance N. 202. Poder legislativo. Imprenta Nacional, San José, Costa Rica. Recuperado de http://www.pgrweb.go.cr/scii/Busqueda/Normativa/Normas/nrm texto completo.aspx?para

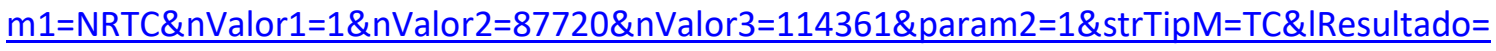
$\underline{2 \& \operatorname{str} \operatorname{Sim}=\operatorname{simp}}$

Ley N. ${ }^{\circ}$ 6826. Ley de Impuesto General sobre las Ventas del 8 de noviembre de 1982 y sus reformas. Recuperado de http://www.pgrweb.go.cr/scii/Busqueda/Normativa/Normas/nrm texto completo.aspx?para m1=NRTC\&nValor1=1\&nValor2=32526\&nValor3=92185\&strTipM=TC

Reglamento de la Canasta Básica Tributaria. Decreto ejecutivo N. ${ }^{\circ}$ 41.615. La Gaceta, 18 de marzo del 2019. Publicado en el Alcance N. ${ }^{\circ} 58$ de La Gaceta. Recuperado de https://www.hacienda.go.cr/docs/5c92588b86431 Decreto\%2041615MEICH\%20Canasta\%20b asica\%202019.pdf

Reglamento de la Ley del Impuesto al Valor Agregado, Decreto Ejecutivo N. ${ }^{\circ} 41779$. La Gaceta, 11 de junio de 2019. Alcance N. $129 . \quad$ Recuperado de https://www.imprentanacional.go.cr/pub/2019/06/11/ALCA129 1106 2019.pdf 